\title{
Heterogeneous Organo- and Metal Catalysis Using Phosphine Oxide Derivatives Anchored on Multiwalled Carbon Nanotubes
}

\author{
Maria Cristina Ligi ${ }^{1}$, Anna Flis ${ }^{2}$, Giacomo Biagiotti ${ }^{1,3}$, Giulia Serrano ${ }^{3,4} \oplus$, \\ K. Michał Pietrusiewicz $2, *$ (D) and Stefano Cicchi $1,3,5, *$ (D) \\ 1 Department of Chemistry, Università di Firenze, via della Lastruccia 3-13, Sesto Fiorentino, \\ 50019 Firenze, Italy; mariacristina.ligi@unifi.it (M.C.L.); giacomo.biagiotti@unifi.it (G.B.) \\ 2 Department of Organic Chemistry, Maria Curie-Skłodowska University, ul. Gliniana 33, \\ 20-614 Lublin, Poland; a.flis@poczta.umcs.lublin.pl \\ 3 INSTM (National Interuniversity Consortium of Materials Science and Technology), Via G. Giusti 9, \\ 50121 Firenze, Italy; giulia.serrano@unifi.it \\ 4 Department of Industrial Engineering, Università di Firenze, via di S. Marta, 3-50139 Firenze, Italy \\ 5 Institute of Chemistry of OrganoMetallic Compounds ICCOM-CNR, Via Madonna del Piano 10, \\ 50019 Sesto Fiorentino, Italy \\ * Correspondence: kazimierz.pietrusiewicz@poczta.umcs.lublin.pl (K.M.P.); stefano.cicchi@unifi.it (S.C.)
}

Received: 10 August 2020; Accepted: 18 September 2020; Published: 21 September 2020

\begin{abstract}
Oxidized multiwalled carbon nanotubes were modified anchoring phosphine oxides and used as heterogeneous catalysts. A proper substitution of the phosphine oxides allowed the use of the Tour reaction and the nitrene cycloaddition to obtain functionalized carbon nanotubes (CNT) with a loading up to $0.73 \mathrm{mmol} / \mathrm{g}$ of material. The catalysts proved efficient in Wittig reactions, Mitsunobu reactions, and Staudinger ligations. Furthermore, the phosphorus decorated CNT were used to produce nanocomposite with Pd nanoparticles able to catalyze Heck reactions.
\end{abstract}

Keywords: carbon nanotube; heterogeneous catalysis; phosphine oxide; wittig reaction; mitsunobu reactions; staudinger ligation

\section{Introduction}

Significant attention in the development of catalytic organophosphorus-based reactions featured last decade [1]. Thanks to the several published studies, important progress in the use of phosphines-mediated reactions for organic synthesis occurred. Substituted phosphines can catalyze many different kind of reactions, recovering their starting oxidation state as the end of the process, such as when they act as nucleophiles in wide range of transformations ranging from Michael to Rauhut-Currier reaction [2]. However, there are several examples in which their oxidation state changes from P(III) to P(V). This is the case of Staudinger ligation [3], Mitsunobu [4], Wittig [5], and Appel [6] reactions in which the byproduct is a phosphine oxide, which is often not easy to remove from the reaction mixture. To obtain a catalytic process it is necessary to add a reduction step in which the former phosphine is recovered. First O'Brien et al. published a catalytic version of the Wittig reaction $[7,8]$. By using a phosphine oxide as pre-catalyst and phenyl silanes as reducing agents, they achieved different alkenes in the presence of either aldehyde or ketone as starting materials. Ashfeld et al. showed a preeminent strategy for amide $\mathrm{C}-\mathrm{N}$ bond construction exploiting a direct traceless Staudinger ligation of carboxylic acids and azides based on phosphine redox catalysis [9]. Mitsunobu reaction catalytic in phosphine was also disclosed by $\mathrm{O}^{\prime}$ Brien and coworkers [7] in the patent literature, and later optimized by Aldrich et al. [10]. The same occurred with the Appel reaction [11]. 
All this literature production is focused on the use of phosphine as homogeneous catalysts [12], whereas no catalyst in heterogeneous phase has been exploited.

On the other hand, carbon nanotubes (CNT) have already demonstrated an efficient support for heterogeneous catalysis both profiting of their high surface area, ability to host a large number of catalytic species $[13,14]$, and their inner space [15]. Their easy functionalization and the large amount of literature produced on their applications [16-20] made them ideal candidates for combining the use of phosphorus derivatives, as active component, and CNT as heterogeneous support, in a catalytic process. This goal was obtained by decorating carbon nanotubes with phosphine oxide derivatives. In this work, we present examples of heterogeneous phosphorus-organocatalysis for the synthesis of small organic molecules in an attempt to explore the potential scope of this approach rather than study in details each process. Our catalytic system consists of a physical support, made of multi walled carbon nanotubes (MWCNT), for triphenyl phosphine oxide or phospholane oxide moieties. The high surface area of carbon nanotubes permits the incorporation of a significant amount of phosphine oxide groups, achieved thanks to an easy functionalization. The phosphorus-based molecules work to promote the organic reactions; the nanostructured carbon material allows an easy separation of products from the reaction mixture and consequently a straightforward purification; at the end of the process the reformed phosphine oxide is not discarded but recycled. The opportunity to reuse the catalyst after the first cycle of reaction is one of the major advantages of heterogeneous organocatalysis, making it a greener process if compared to chemical reactions carried out in homogeneous phase. To the best of our knowledge this is one of the few heterogeneous organocatalytic process described by $[21,22]$ in the literature, and the first using phosphine oxides.

In a previous work [23], we have shown how it is possible to covalently functionalize carbon based nanostructured materials using amino substituted and azido substituted phosphine derivatives to prepare new materials that have been preliminarily tested in a Staudinger ligation experiment. Here, we extend the use of the catalysts to Wittig and Mitsunobu reactions and demonstrate the possibility of a different use of the same material in which the phosphine moieties act as ligand for Pd nanoparticles to afford a nanocomposite that can catalyze the Heck reaction [24]. The Heck reaction is a useful method for forming $\mathrm{C}-\mathrm{C}$ bond on the double bond carbon atoms, with a wide application in organic synthesis [25].

\section{Materials and Methods}

MWCNTs were purchased from Sigma-Aldrich reagent, O.D. $\times$ L. $=6-9 \mathrm{~nm} \times 5 \mu \mathrm{m}$, carbon $>95 \%$, CoMoCat $($ ). All the other reagents, whose synthesis is not described, were commercially available and were used without any further purification, if not specified otherwise. $R_{\mathrm{f}}$ values are referred to TLC on silica gel plate $(0.25 \mathrm{~mm}$, Merck silica gel 60 F254). NMR spectra were recorded on Varian Gemini $200 \mathrm{MHz}$ or Varian Mercury $400 \mathrm{MHz}$ at room temperature. Chemical shifts were reported in parts per million (ppm) relative to the residual solvent peak rounded to the nearest 0.01 for proton and 0.1 for carbon (reference: $\mathrm{CHCl}_{3}\left[{ }^{1} \mathrm{H}: 7.26,{ }^{13} \mathrm{C}: 77.0\right]$. Coupling constants J were reported in $\mathrm{Hz}$ to the nearest $0.01 \mathrm{~Hz}$. Peak multiplicity was indicated by s (singlet), d (doublet), t (triplet), q (quartet), m (multiplet), and br (broad signal). IR spectra were recorded on a Perkin-Elmer FT-IR 881 or Shimadzu FT-IR $8400 \mathrm{~s}$ spectrometer. IR data are reported as frequencies in wavenumbers $\left(\mathrm{cm}^{-1}\right)$. Elemental analyses were performed with a Thermofinnigan CHN-S Flash E1112 analyzer. ICP analysis were made using an Optima 2000 Perkin Elmer Inductively Coupled Plasma (ICP) Dual Vision instrument after acidic mineralization. Transmission electron microscopy (TEM) images were acquired at the electronic microscopic center CNR Florence (CE.M.E.) with a Philips CM12 with CRYO-GATAN UHRST 3500 technology, digital camera, and EDAX microanalysis. 


\subsection{X-ray Photoelectron Spectroscopy (XPS) Analysis}

XPS measurements were carried out using a non-monochromatic X-ray source (VSW-TA10 Mg K $\alpha$ radiation, $1253.6 \mathrm{eV})$ operating at $120 \mathrm{~W}(12 \mathrm{kV}$ and $10 \mathrm{~mA})$ and a VSW-HA100 hemispherical analyzer mounting a 16-channel detector and operating in fixed pass energy mode $(44 \mathrm{eV})$.

The samples were obtained by a dropcast of dispersions of 8 in a dichloromethane solution ( $\geq 99.8 \%$ from Sigma-Aldrich) on Au/mica substrates.

XPS peak components were deconvoluted using the CasaXPS software using mixed Gaussian and Lorentzian contributions and setting identical FWHM for each component of the same element. Spectra background was fitted using linear or Shirley methods [26]; spectra of all samples were calibrated to the Au $4 f_{7 / 2}$ signal at a binding energy (B.E.) of $84.0 \mathrm{eV}$ according to the literature [27].

Compounds 3 [28], 4, 6 and 7, 9 and 10 [23] were synthesized following published procedures.

\subsection{Synthesis of 3-azido-1-phenylphospholane 1-oxide 5}

Synthesis of this compound was accomplished by modification of the previously developed procedures $[29,30]$.

\subsection{Synthesis of 1-phenyl-3-benzylaminophospholane 1-oxide A}

In a Schlenk flask equipped with a magnetic stirrer was placed $1.78 \mathrm{~g}$ of phosphol-2-ene 1-oxide, $10.71 \mathrm{~g}(100 \mathrm{mmol})$ of benzylamine, and $10 \mathrm{~mL}$ of water. The resulting mixture was heated at $110^{\circ} \mathrm{C}$ for $72 \mathrm{~h}$. After cooling to room temperature, the reaction mixture was extracted with chloroform $(3 \times 30 \mathrm{~mL})$, the extracts were combined, dried over anhydrous $\mathrm{MgSO}_{4}$, filtered, and evaporated. The excess of benzylamine was distilled off in vacuo to give crude product in the form of two diastereoisomers in ca. 1:2.5 ratio ( ${ }^{31} \mathrm{P}$ NMR: $\delta 58.63$ and $56.38 \mathrm{ppm}$, respectively). Final purification of this mixture on a silica gel column using chloroform/methanol mixture (15:1) as eluent afforded $1.36 \mathrm{~g}$ $(48 \%)$ of pure major adduct as an oil.

${ }^{1} \mathrm{H}$ NMR $\left(\mathrm{CDCl}_{3}\right) \delta 1.58$ (bs, $\left.1 \mathrm{H}\right), 1.95-2.07(\mathrm{bm}, 2 \mathrm{H}), 2.07-2.36(\mathrm{bm}, 3 \mathrm{H}), 2.37-2.46(\mathrm{~m}, 2 \mathrm{H})$, $3.35-3.46(\mathrm{~m}, 1 \mathrm{H}), 3.89(\mathrm{q}, \mathrm{J}=13.1 \mathrm{~Hz}, 2 \mathrm{H}), 7.26-7.32(\mathrm{~m}, 1 \mathrm{H}), 7.33-7.39(\mathrm{~m}, 4 \mathrm{H}), 7.48-7.59(\mathrm{~m}, 3 \mathrm{H})$, and $7.68-7.76(\mathrm{~m}, 2 \mathrm{H})$.

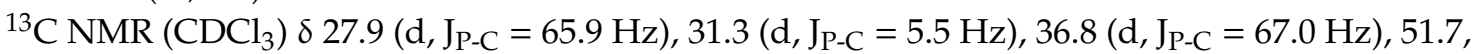
$57.2\left(\mathrm{~d}, \mathrm{~J}_{\mathrm{P}-\mathrm{C}}=12.2 \mathrm{~Hz}\right), 127.1,128.0,128.5,128.7\left(\mathrm{~d}, \mathrm{~J}_{\mathrm{P}-\mathrm{C}}=12.5 \mathrm{~Hz}\right), 129.8\left(\mathrm{~d}, \mathrm{~J}_{\mathrm{P}-\mathrm{C}}=11 ., 4 \mathrm{~Hz}\right), 131.6$ $\left(\mathrm{d}, \mathrm{J}_{\mathrm{P}-\mathrm{C}}=2.7 \mathrm{~Hz}\right), 134.4\left(\mathrm{~d}, \mathrm{~J}_{\mathrm{P}-\mathrm{C}}=91.6 \mathrm{~Hz}\right)$, and 139.8 .

${ }^{31} \mathrm{P} \mathrm{NMR}\left(\mathrm{CDCl}_{3}\right) \delta 56.38 \mathrm{ppm}$.

Elemental analysis calculated for $\mathrm{C}_{17} \mathrm{H}_{20} \mathrm{NOP}$ : C, 71.61; H, 7.06; found $\mathrm{C}, 71.45 ; \mathrm{H}, 6.99$.

The minor adduct was washed from the column in the first fraction together with unreacted phosphol-2-ene 1-oxide and was not separated. Considering that the double bond in phosphol-2-ene oxides is known to undergo attacks by the incoming reagents exclusively, or at least preferentially, from the side opposite to the bigger P-substituent [31,32], the stereochemical array of the 3-amino and $\mathrm{P}$-Ph substituents in the major adduct is tentatively assigned as "anti".

\subsection{3-Azido-1-Phenylphospholane 1-Oxide 5}

A solution of sodium azide (333 mg, $5.12 \mathrm{mmol})$ in $\mathrm{H}_{2} \mathrm{O}(1.7 \mathrm{~mL})$ and $\mathrm{CH}_{2} \mathrm{Cl}_{2}(0.5 \mathrm{~mL})$ was added with a solution of trifluoromethanesulfonic anhydride $(233 \mathrm{mg}, 1.02 \mathrm{mmol})$ in $\mathrm{CH}_{2} \mathrm{Cl}_{2}(1 \mathrm{~mL})$ at $0{ }^{\circ} \mathrm{C}$. The resulting suspension was stirred for $10^{\prime}$ at $0^{\circ} \mathrm{C}$ and at room temperature for $3 \mathrm{~h}$. After the addition of $5 \mathrm{~mL}$ of $\mathrm{H}_{2} \mathrm{O}$ the mixture was extracted three times with $\mathrm{CH}_{2} \mathrm{Cl}_{2}(10 \mathrm{~mL})$. The combined organic extracts were first washed with a saturated solution of $\mathrm{Na}_{2} \mathrm{CO}_{3}$, then stored.

$\mathrm{CuSO}_{4}(0.9 \mathrm{mg}, 0.005 \mathrm{mmol})$ and $\mathrm{K}_{2} \mathrm{CO}_{3}(106 \mathrm{mg}, 0.77 \mathrm{mmol})$ were added to a solution of $\mathbf{A}$ (100 mg, $0.512 \mathrm{mmol})$ in $\mathrm{H}_{2} \mathrm{O} / \mathrm{MeOH}(7 \mathrm{~mL} / 18 \mathrm{~mL})$. The stirring solution was mixed to the previously achieved solution. After $19 \mathrm{~h}$ the reaction was completed. $\mathrm{R}_{\mathrm{f}}(\mathrm{EtOAc} / \mathrm{MeOH} 5: 1)=0.9$. The mixture was extracted five times with $\mathrm{CH}_{2} \mathrm{Cl}_{2}(15 \mathrm{~mL})$. The combined organic extracts were washed with brine 
(35 mL), dried over anhydrous $\mathrm{MgSO}_{4}$, filtered, and evaporated in vacuo to afford $\mathbf{5}$ as a white solid. ( $80 \mathrm{mg}, 71 \%$ yield).

IR spectrum $v \mathrm{~cm}^{-1} 2100 \mathrm{~s}, 1710 \mathrm{~s}$ (see SI: Figure S3).

${ }^{1} \mathrm{H}$ NMR $(400 \mathrm{MHz}, 298 \mathrm{~K}, \mathrm{CDCl} 3) \delta 7.69-7.63(\mathrm{~m}, 2 \mathrm{H}), 7.53-7.44(\mathrm{~m}, 3 \mathrm{H}), 4.20-4.11(\mathrm{~m}, 2 \mathrm{H})$, and 2.37-2.02 (m, 7H) (see SI: Figure $\mathrm{S} 4)$.

${ }^{13} \mathrm{C}$ NMR (see SI: Figure S5).

gCosy NMR (see SI: Figure S6).

MS-ESI 244.0, (M + Na) 464.8 (2M + Na) (see SI: Figure S7).

\subsection{Oxidized MWCNT (2)}

The oxidation of carbon nanotubes was performed following literature procedure [23].

Yield 39\% (194.6 mg); FT-IR: 3420, 1707, 1571, 1391, and $1211 \mathrm{~cm}^{-1}$ (see SI: Figures S8 and S9).

Elemental analysis $\mathrm{C}, 77.72 ; \mathrm{H}, 0.84 ; \mathrm{N}, 0.19 \%$.

\subsection{Synthesis of 8}

A $100 \mathrm{~mL}$ flask was added with CNT (20 mg) and $40 \mathrm{~mL}$ of 1,2-dichlorobenzene. The mixture was kept in an ultrasound bath for $20 \mathrm{~min}$. 3-azido-1-phenylphospholane 1-oxide (5) (60 mg $0.27 \mathrm{mmol}$ ) was added. The dispersion was kept at $165^{\circ} \mathrm{C}$ under vigorous stirring for 4.5 days. The dispersion was diluted with isopropanol and centrifuged for $15 \mathrm{~min}$ at $1500 \mathrm{rcf}$. The supernatant was removed. The precipitate was washed, dispersed, and centrifugated ( $5 \mathrm{~min}$ in ultrasound bath and centrifugation for $15 \mathrm{~min}$ at $1500 \mathrm{rcf}$ ) with a solution of diisopropyl ether and isopropanol 1:1. After the removal of supernatant, the solid was washed by cycle of dispersion in fresh methanol and centrifugation (two times). The product was recovered and dried to afford $66.8 \mathrm{mg}$ of a black powder. FTIR (KBr): $3380,1713,1586,1159$, and $1123 \mathrm{~cm}^{-1} \mathrm{P}=\mathrm{O}$ stretching (see SI: Figure S12).

\subsection{Synthesis of Pd Nanocomposite (20)}

In a $5 \mathrm{~mL}$ flask, $5.2 \mathrm{mg}(0.023 \mathrm{mmol})$ of $\mathrm{Pd}(\mathrm{OAc})_{2}$ were added to a dispersion of $12.9 \mathrm{mg}$ of $\mathbf{1 0}$ in $3 \mathrm{~mL}$ of ethanol. The mixture was kept under hydrogen atmosphere for $24 \mathrm{~h}$. The reaction mixture was filtered through a polycarbonate membrane filter (pore diameter: $0.2 \mu \mathrm{m})$ and the solid washed $(30 \mathrm{~mL}$ of ethanol) and dried. The product was recovered as $15.9 \mathrm{mg}$ as a black powder.

\subsection{Reaction Procedures}

\subsubsection{Procedure for the Wittig Reaction}

A Pyrex tube equipped with a stirring bar was charged with 8 or $9(6 \mathrm{mg})$ and $0.2 \mathrm{~mL}$ of dry toluene. After $5 \mathrm{~min}$ in an ultrasonic bath, DIPEA (10 mg, $1.2 \mathrm{eq})$, benzaldehyde (7.5 mg, $1 \mathrm{eq})$, methyl bromoacetate (13 mg, $1.2 \mathrm{eq})$, diphenyl silane $(26 \mathrm{mg}, 2 \mathrm{eq})$, and $0.1 \mathrm{~mL}$ of dry toluene were added to the mixture. The reaction was heated at $100{ }^{\circ} \mathrm{C}$ for $24 \mathrm{~h}$. The catalyst was recovered first by centrifugation $(2 \times 15 \mathrm{~min}$ at $1500 \mathrm{rcf})$ and dispersion with toluene $20 \mathrm{~mL}$, then same procedure using methanol $(20 \mathrm{~mL})$. The solution was evaporated under vacuum affording the crude product. After flash chromatography (silica) using a mixture of hexane/ethyl acetate 10:1 the product was achieved as white solid. The recovered solid catalyst was washed thoroughly with dry toluene $(3 \mathrm{~mL})$, separated by centrifugation $(\times 3)$, dried under vacuum, weighted, and used for another run.

GC-MS Spectrum (EI) retention time: $12.4^{\prime} . \mathrm{m} / \mathrm{z} 163(\mathrm{M}+1)$ (see SI: Figure S17).

${ }^{1} \mathrm{H}-\mathrm{NMR}\left(400 \mathrm{MHz}, 298 \mathrm{~K}, \mathrm{CDCl}_{3}\right) \delta 7.70(\mathrm{~d}, \mathrm{~J}=16.0 \mathrm{~Hz}, 1 \mathrm{H}), 7.53-7.51(\mathrm{~m}, 2 \mathrm{H}), 7.38-7.36(\mathrm{~m}, 3 \mathrm{H})$, and $6.44(\mathrm{~d}, \mathrm{~J}=16.0 \mathrm{~Hz}, 2 \mathrm{H})$ (see SI: Figure S18).

\subsubsection{Procedure for the Mitsunobu Reaction}

A Pyrex tube equipped with a stirring bar was charged with $8(5 \mathrm{mg})$ and $0.3 \mathrm{~mL}$ of THF. After $5 \mathrm{~min}$ in an ultrasonic bath, 4-nitro benzoic acid ( $42 \mathrm{mg}, 1.5 \mathrm{eq})$, benzyl alcohol (18 mg, $1 \mathrm{eq})$, diisopropyl 
azodicarboxylate ( $38 \mathrm{mg}, 1.1 \mathrm{eq})$, phenyl silane ( $27 \mathrm{mg}$, $1.5 \mathrm{eq}$ ) were added to the mixture. The reaction was heated at $80{ }^{\circ} \mathrm{C}$ for $24 \mathrm{~h}$. The reaction mixture was filtered through a PTFE membrane filter (pore diameter: $0.2 \mu \mathrm{m}$ ). The catalyst was washed with fresh tetrahydrofuran and recovered. The solution was evaporated under vacuum giving the crude product. After flash chromatography (silica) using a mixture of hexane/ethyl acetate 20:1 benzyl 4-nitrobenzoate was achieved as a yellow solid.

GC-MS Spectrum (EI) retention time: 21.5'. $257(\mathrm{M}+1) \mathrm{m} / \mathrm{z}$ (see SI: Figure S19).

${ }^{1} \mathrm{H}-\mathrm{NMR}\left(400 \mathrm{MHz}, 298 \mathrm{~K}, \mathrm{CDCl}_{3}\right) \delta 8.30-8.23(\mathrm{q}, \mathrm{J}=9.2 \mathrm{~Hz}, 4 \mathrm{H}), 7.48-7.37(\mathrm{~m}, 5 \mathrm{H})$, and 5.42 $(\mathrm{s}, 2 \mathrm{H})$ (see SI: Figure S20).

\subsubsection{Procedure for the Staudinger Ligation}

A Pyrex tube was added with $10(5 \mathrm{mg})$ degassed dry toluene $(1 \mathrm{~mL})$, carboxyl acid $(0.19 \mathrm{mmol}$, $1 \mathrm{eq})$, a solution of benzyl azide $(0.19 \mathrm{mmol})$ in $0.5 \mathrm{~mL}$ of degassed toluene and phenyl silane $\left(21 \mathrm{mg}, 0.19 \mathrm{mmol}, 1 \mathrm{eq}\right.$ ) and the reaction was stirred at $110{ }^{\circ} \mathrm{C}$ under nitrogen atmosphere for $24 \mathrm{~h}$. The catalyst was recovered by dispersion with $20 \mathrm{~mL}$ of toluene and centrifugation 2 times for $15 \mathrm{~min}$ at $1500 \mathrm{rcf}$. The solution was evaporated under vacuum giving the crude product. The amide was recovered after flash chromatography (silica) using a mixture of hexane/ethyl acetate 1:1. N-Benzylbenzamide: $R_{\mathrm{f}}=0.48$.

GC-MS spectrum (CI) retention time: $23.0^{\prime}$. m/z $212(\mathrm{M}+1)$. (see SI: Figure S15) ${ }^{1} \mathrm{H}-\mathrm{NMR}(200 \mathrm{MHz}$, $\left.298 \mathrm{~K}_{,} \mathrm{CDCl}_{3}\right) \delta 7.79(\mathrm{~d}, \mathrm{~J}=9.6 \mathrm{~Hz}, 2 \mathrm{H}), 7.51-7.29(\mathrm{~m}, 8 \mathrm{H}), 6.44(\mathrm{bs}, 1 \mathrm{H})$, and $4.65(\mathrm{~d}, \mathrm{~J}=5.6 \mathrm{~Hz}, 2 \mathrm{H})$ (see SI: Figure S16).

\subsubsection{Control Experiments}

To rule out any possible role of the starting ox-MWCNTs 2 or of absorbed phosphine oxide derivatives onto CNT walls, some control experiments were performed.

A $100 \mathrm{~mL}$ flask was added with CNT (20 mg) and $40 \mathrm{~mL}$ of 1,2-dichlorobenzene. The mixture was kept in an ultrasound bath for $20 \mathrm{~min}$. Triphenylphosphine oxide $(75 \mathrm{mg} 0.27 \mathrm{mmol}$ ) was added. The dispersion was kept at $165{ }^{\circ} \mathrm{C}$ under vigorous stirring for 4.5 days. The dispersion underwent the same purification procedure as reported for material $\mathbf{8}$ to afford $16 \mathrm{mg}$ of material (2a) as a black powder. Both $\mathbf{2}$ and 2a were used as catalysts in the Wittig, Staudinger ligation, and Mitsunobu reaction. No product formation was observed in each case.

\subsubsection{Procedure for Heck Reaction}

A Pyrex tube was added with catalyst $20(3.5 \mathrm{mg})$, potassium carbonate (138 $\mathrm{mg}, 2 \mathrm{eq})$, $\mathrm{N}, \mathrm{N}$-dimethyl formamide $(1.5 \mathrm{~mL})$, alkene $(1.2 \mathrm{eq})$, and iodobenzene $(79 \mathrm{mg}, 1 \mathrm{eq})$ and the reaction was stirred at $120^{\circ} \mathrm{C}$ for $6 \mathrm{~h}$. The reaction mixture was diluted with $20 \mathrm{~mL}$ of isopropyl alcohol and centrifuged at $1500 \mathrm{rcf}$ for $15^{\prime}$. The catalyst was recovered.

After flash chromatography the product was recovered.

Trans-stilbene (hexane: ethyl acetate 2:1), was obtained as a white solid.

GC-MS Spectrum (CI) retention time: $29.1^{\prime} . \mathrm{m} / \mathrm{z} 181(\mathrm{M}+1)$ (see SI: Figure S21).

${ }^{1} \mathrm{H}-\mathrm{NMR}\left(200 \mathrm{MHz}, 278 \mathrm{~K}, \mathrm{CDCl}_{3}\right) \delta 7.53(\mathrm{~d}, \mathrm{~J}=6.8 \mathrm{~Hz}, 4 \mathrm{H}), 7.41-7.30(\mathrm{~m}, 6 \mathrm{H}), 7.12(\mathrm{~s}, 2 \mathrm{H})($ see SI: Figure S22).

Trans-cinnamic acid (hexane: dichloromethane 20:1), was obtained as a white solid.

GC-MS Spectrum (CI) retention time 15.3'. m/z $149(\mathrm{M}+1)$ (see SI: Figure S23).

${ }^{1} \mathrm{H}-\mathrm{NMR}\left(200 \mathrm{MHz}, 298 \mathrm{~K}, \mathrm{CDCl}_{3}\right) \delta 7.81(\mathrm{~d}, \mathrm{~J}=16 \mathrm{~Hz} 1 \mathrm{H}), 7.59-7.52(\mathrm{~m}, 2 \mathrm{H}), 7.46-7.40(\mathrm{~m}, 3 \mathrm{H})$, and $6.47(\mathrm{~d}, \mathrm{~J}=16 \mathrm{~Hz}, 1 \mathrm{H})$ (see SI: Figure S24).

\section{Results}

The synthesis of the heterogeneous catalysts started from pristine MWCNT (1) that were oxidized using a $\mathrm{HNO}_{3} / \mathrm{H}_{2} \mathrm{SO}_{4}$ mixture at $100{ }^{\circ} \mathrm{C}$ for $30 \mathrm{~min}$. The oxidation removed any metal impurity, shortened the nanotubes (see Supporting Material, Figure S8), and improved their dispersibility in most 
solvent due to the insertion of oxygenated functional groups as shown by IR spectra (SI, Figure S9). The oxidized multiwalled carbon nanotubes (Ox-MWCNTs) 2 were used as substrate for the reaction with three different phosphine oxide derivatives: (4-aminophenyl)diphenyl phosphine oxide (3) [28]; (4-azidophenyl)diphenyl phosphine oxide (4) [23], and 3-azido-1-phenylphospholane 1-oxide (5) (Chart 1). Compound $\mathbf{5}$ was synthetized for this study since it is an analogue of the phospholane derivatives used by $\mathrm{O}^{\prime}$ Brien [8] and Aldrich [10] in their works: the presence of an azido group allowed an easy functionalization of the CNT. The synthesis started from phosphol-2-ene 1-oxide modifying a previous procedure [29-31].<smiles>[X]c1ccc([PbH])cc1</smiles>

$$
\begin{aligned}
& 3 X=\mathrm{NH}_{2} \\
& 4 X=\mathrm{N}_{3}
\end{aligned}
$$<smiles>NC1CCP(=O)(c2ccccc2)C1</smiles>

5

Chart 1. Structure of starting phosphine oxides 3, 4 and of phospholane 5.

The three compounds were used to covalently decorate the nanotubes 2 using the Tour protocol [33,34] for the amino derivative 3 (Scheme 1, Equation (1)) to afford compound $\mathbf{6}$, while profiting of the reactivity of the azido group, in compound 4 and 5, towards carbon nanotube walls at high temperature [35] to afford compounds 7 and 8, respectively (Scheme 1, Equations (2) and (3), the synthesis of compounds 6 and 7 was described on ref [23]).

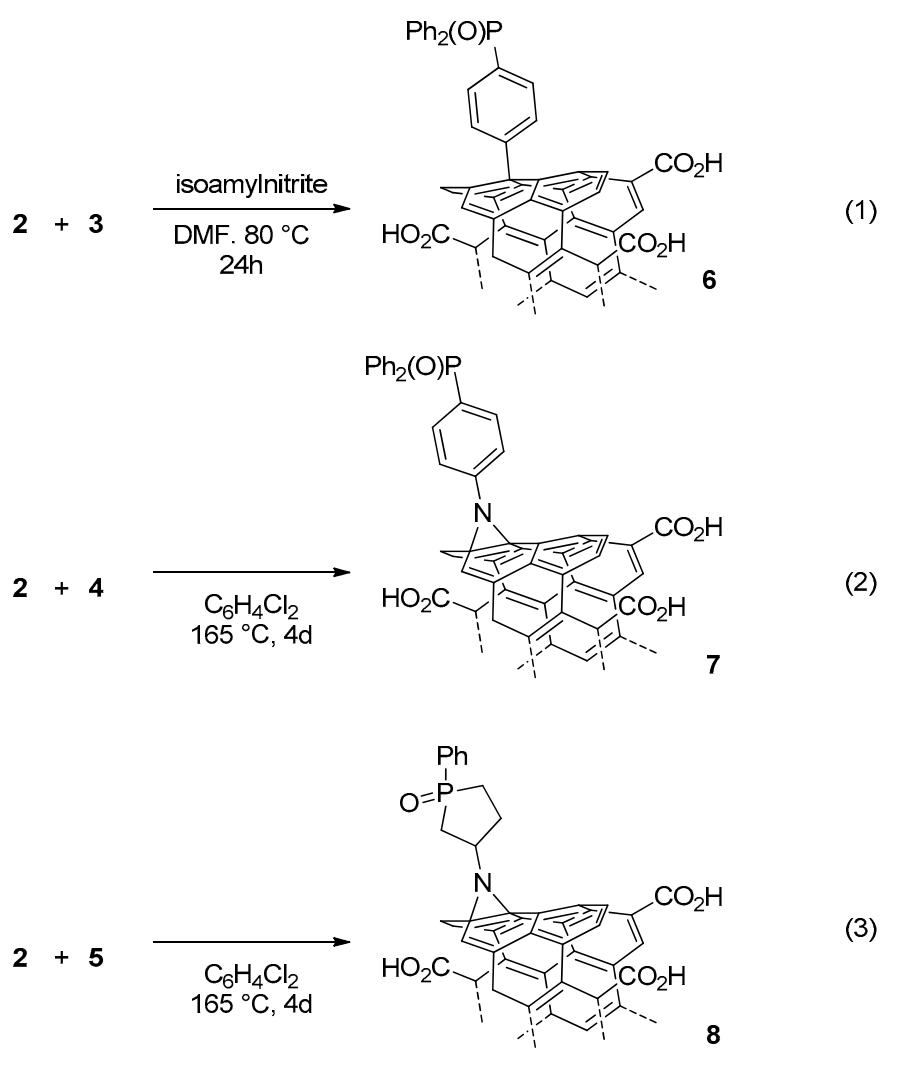

Scheme 1. Synthesis of 6, 7 and 8. 
The loading of the resulting materials can be evaluated using different techniques. A simple IR spectrum, for examples, can afford qualitative evaluation of the successful reaction based on the appearance of an intense band at $1140 \mathrm{~cm}^{-1}$ due to the $\mathrm{P}=\mathrm{O}$ stretching [36]. All the IR spectra of materials 6, 7, and 8 showed this diagnostic band (see SI, Figures S10-S12). In the previous work, XPS analyses unambiguously demonstrated the presence of the phosphine oxides groups on the CNT surfaces for compound 6 and 7 [23].

A quantitative evaluation can also be offered by inductively coupled ion plasma atomic emission spectroscopy (ICP-AES) analyses evaluating the amount of phosphorus present on material 6-8 (Table 1).

Table 1. Content of phosphorus calculated using ion plasma atomic emission spectroscopy (ICP-AES).

\begin{tabular}{|c|c|c|}
\hline Compound & ICP/AES P\% ${ }^{a}$ & $\mathrm{mmol} / \mathrm{g} \mathrm{P}$ \\
\hline 6 & 1.84 & 0.59 \\
\hline 7 & 2.25 & 0.73 \\
\hline 8 & 2.09 & 0.67 \\
\hline
\end{tabular}

The $\%$ content of nitrogen, estimated by elemental analyses, for compound $7(1.12 \% \pm 0.15)$, was in accordance with the loading degree suggested by ICP-AES. (Table 1). The synthetic approach consisting of nitrene cycloaddition provided a slightly higher loading both for compound $\mathbf{7}$ and $\mathbf{8}$ if compared to compound 6 .

The following chemical transformation was the reduction of phosphine oxides 6 and 7 to the corresponding phosphines (catalysts 9 and 10, Chart 2), using trichloro silane, as already reported in our previous work [23]. In our previous work we demonstrated the successful reduction using an XPS analysis but the same qualitative information can be obtained from a simple IR spectrum showing the disappearance of the $\mathrm{P}=\mathrm{O}$ stretching band at $1100 \mathrm{~cm}^{-1}$. (IR spectrum SI: Figures $\mathrm{S} 13$ and S14).


Chart 2. Structure of catalysts 9 and $\mathbf{1 0 .}$

The new adduct 8 was also characterized by XPS analysis. Elemental analysis performed by XPS evidences the presence of $C 1 s, N$ s, and P $2 p$ signals as expected from the structure of the functionalized MWNTs (Table 2, Entry 1). We expect that the $C$ 1s signal is affected by contamination during dropcast preparation and their manipulation in air. However, the samples show that the ratio between the P 2p and N 1s XPS signals (P/N, Table 2, Entry 1) is close to one, confirming the presence of the substituted phosphine oxide group before and after the catalytic cycles. 
Table 2. X-ray Photoelectron Spectroscopy (XPS) semi-quantitative analysis of 8 dropcasted on Au/mica.

\begin{tabular}{cccccc}
\hline Entry & Substrate & $\mathbf{C}$ 1s & N 1s & P 2p & P/N \\
\hline 1 & 8 & $91 \%$ & $4.56 \%$ & $4 \%$ & 0.90 \\
2 & $8^{\text {a }}$ & $96 \%$ & $1.91 \%$ & $2 \%$ & 0.99 \\
\hline \multicolumn{7}{c}{ a Catalyst 8 after three catalytic cycles. }
\end{tabular}

XPS spectra of the P $2 p$ region for 8 are shown (Figure 1a) shows the presence of two peaks at $134.0 \mathrm{eV}$ and $134.9 \mathrm{eV}$ corresponding to the $\mathrm{P} 2 \mathrm{p}_{3 / 2}$ and $\mathrm{P} 2 \mathrm{p}_{1 / 2}$ spin orbit components [27]. Their binding energy indicates the only presence of phosphine oxide groups detected in similar compounds, thus evidencing that no degradation of the functional group occurs [23].

(a)

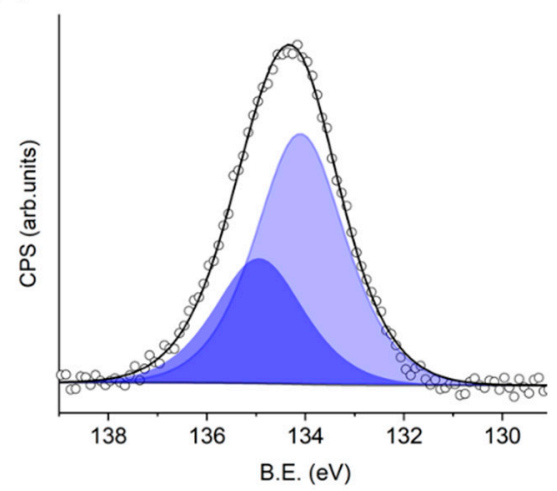

(b)

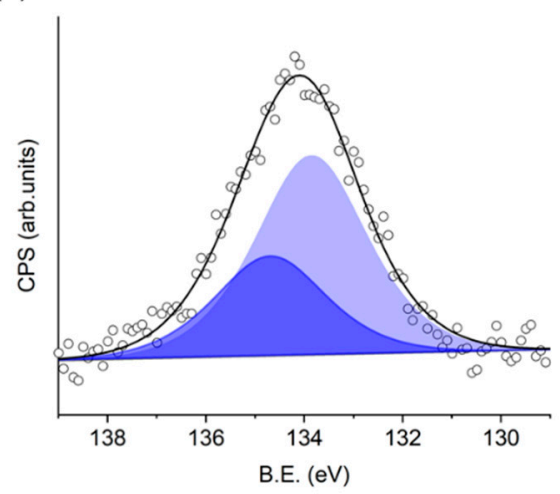

Figure 1. XPS P 2p spectra of $\mathbf{8}$ dropcasted on Au/mica: (a) as produced, (b) after 3 catalytic cycles. Empty circles represent the experimental data, black solid line represent the convolution of the fitted two spin orbit components (blue areas).

Inspired by O'Brien and coworkers [8], who demonstrated the application of the catalytic Wittig methodology by using 3-methyl-1-phenylphospholane 1-oxide as catalyst, the material 8, carrying a similar substituent on the nanotube surface, was tested as heterogeneous organocatalyst in a Wittig reaction. Methyl bromoacetate (12) and benzaldehyde (11) were reacted to afford methyl cinnamate (13) in three repeated reaction cycles (Scheme 2, Table 3). As base, DIPEA was preferred to $\mathrm{Na}_{2} \mathrm{CO}_{3}$ since it made easier to recycle the solid catalyst controlling the amount of base present in the reaction vessel.<smiles>O=Cc1ccccc1</smiles>

11<smiles>COC(=O)CBr</smiles>

12



$100^{\circ} \mathrm{C}, 24 \mathrm{~h}$<smiles>COC(=O)/C=C/c1ccccc1</smiles>

13

Scheme 2. The Witting reaction of $\mathbf{1 1}$ and $\mathbf{1 2}$ to afford cinnamate $\mathbf{1 3 .}$

Table 3. Catalytic Wittig reaction: yields of methyl cinnamate (13) over the different cycles.

\begin{tabular}{cccccc}
\hline Entry & Catalyst & Amount of Phosphole (mmol \%) & Cycle 1 & Cycle 2 & Cycle 3 \\
\hline 1 & $\mathbf{8}$ & 5.7 & $70 \%$ & $52 \%$ & $25 \%$ \\
2 & $\mathbf{9}$ & 5 & $55 \%$ & $24 \%$ & - \\
\hline
\end{tabular}


The catalytic process was guaranteed by the presence of $\mathrm{Ph}_{2} \mathrm{SiH}_{2}$ that reduced the phospholane oxide to the reacting phospholane at the beginning of every reaction cycle. Comparing our system with the results collected by $\mathrm{O}^{\prime}$ Brien and coworkers (methyl cinnamate was obtained up to $80 \%$ yield using 0.1 equivalent of phosphole), the performances of catalyst 8 is comparable for the first cycle (Table 2, Entry 1) to the results obtained in solution considering that the reaction was conducted with an amount of catalysts corresponding to 0.06 equivalent of phospholane. Unluckily the catalyst efficiency degraded quickly in the second and third cycles. (Table 2, Entry 1). The same reaction was performed using catalyst 9 (0.05 equivalents of phosphine substituent) with lower yields (Table 3 Entry2). Increasing the amount of catalysts, up to 0.1 equivalent did not increase the yields, while any reduction did not afford any product. This adopted heterogeneous organocatalysis allows a recycle of catalyst for both compounds $(\mathbf{8}, \mathbf{9})$ : after an easy filtration, the decorated CNTs were suitable for the successive synthetic cycle.

The same redox driven approach, involving phosphorus compound with different valence, could be applied for Mitsunobu catalytic reaction. Again, inspired by the work of Aldrich and coworkers [10], who used 1-phenylphospholane 1-oxide as catalyst (5\%), we used catalyst 8 for the synthesis of the benzyl 4-nitrobenzoate (16) (Scheme 3) following Aldrich's procedure: refluxing THF in the presence of diisopropyl azodicarboxylate and phenyl silane as reducing agent.

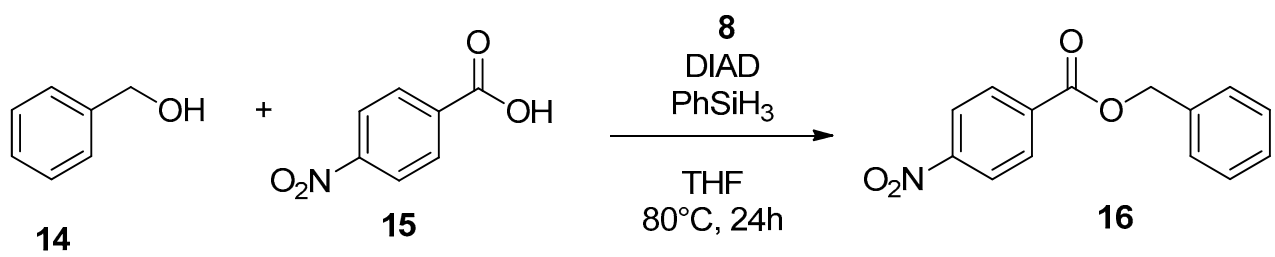

Scheme 3. The Mitsunobu reaction of $\mathbf{1 4}$ and 15 to afford benzoate $\mathbf{1 6}$.

The reaction was conducted using an amount of 8 corresponding to $2 \%$ mol of phospholane derivative obtaining for the first cycle a conversion of $54 \%$ (Table 4) Again, the efficiency of the catalyst decreased rapidly in the second and third cycles and the amount of catalyst was critical to obtain acceptable yields.

Table 4. Catalytic Mitsunobu reaction: yields of benzoate 16 over the different cycles.

\begin{tabular}{ccccc}
\hline Catalyst & Amount of Phosphole (mmol \%) & Cycle 1 & Cycle 2 & Cycle 3 \\
\hline $\mathbf{8}$ & 2 & $54 \%$ & $40 \%$ & $22 \%$ \\
\hline
\end{tabular}

Both the processes analyzed evidenced a progressive deterioration of the catalytic activity. The results of an XPS analysis of $\mathbf{8}$ after three catalytic cycles are reported in Table 2 Entry 2 and Figure $1 \mathrm{~b}$. The analysis confirms that the N/P ratio is still 1:1 (Table 2 Entry 2 ) and that the phosphine oxide functional group is present (Figure $1 b$ ). These results suggest that the progressive decrease of the reaction yield is probably not due to decomposition of $\mathbf{8}$ but to the reduction process of the phosphine oxide that become less efficient increasing the catalytic cycles.

Catalysts $\mathbf{9}$ and $\mathbf{1 0}$ were, then, used in a Staudinger Ligation reaction. Compound $\mathbf{1 0}$ was already used in our previous work [23]. Here we report a comparison of the activity of catalyst 9 and catalyst 10 in the Staudinger ligation reaction between benzoic acid (17) and benzyl azide (18) to obtain N-benzyl benzamide (19). (Scheme 4) using the same reaction conditions as reported by Ashfeld and coworkers: [9] refluxing toluene in the presence of phenyl silane and the catalyst (triphenyl phosphine $(10 \% \mathrm{~mol})$ in the case of the work of Ashfeld and catalysts $\mathbf{9}$ or $\mathbf{1 0}$ (1\% mol of phosphorus moiety) in this work) 
<smiles>O=C(O)c1ccccc1</smiles>

17<smiles>N#CCc1ccccc1</smiles>

18



$110^{\circ} \mathrm{C}, 24 \mathrm{~h}$<smiles>O=C(NCc1ccccc1)c1ccccc1</smiles>

19

Scheme 4. The Staudinger ligation reaction of $\mathbf{1 7}$ and $\mathbf{1 8}$ to afford benzamide 19.

The results reported in Table 5 show that catalysts $\mathbf{9}$ and $\mathbf{1 0}$ perform very similarly and regardless of the different way in which the triphenylphosphine group is linked to the nanotube surface. Again, the catalysts efficiency decreases rapidly upon recycling in the following reaction cycles.

Table 5. Catalytic Staudinger ligation: yields of benzamide 19 over the different cycles.

\begin{tabular}{cccccc}
\hline Entry & Catalyst & Amount of Phosphine (mmol \%) & Cycle 1 & Cycle 2 & Cycle 3 \\
\hline 1 & $\mathbf{9}$ & 1 & $75 \%$ & $30 \%$ & $20 \%$ \\
2 & $\mathbf{1 0}$ & 1 & $69 \%$ & $34 \%$ & $21 \%$ \\
\hline
\end{tabular}

Finally, adduct 10 was tested as support for Pd nanoparticles to produce a new nanocomposite (adduct 20) in which the phosphine groups might play the role to coordinate and stabilize catalytically active $\operatorname{Pd}(0)$ nanoparticles. The nanoparticles were produced, in the presence of adduct 10, upon reduction of $\mathrm{Pd}$ acetate in hydrogen atmosphere (Scheme 5).

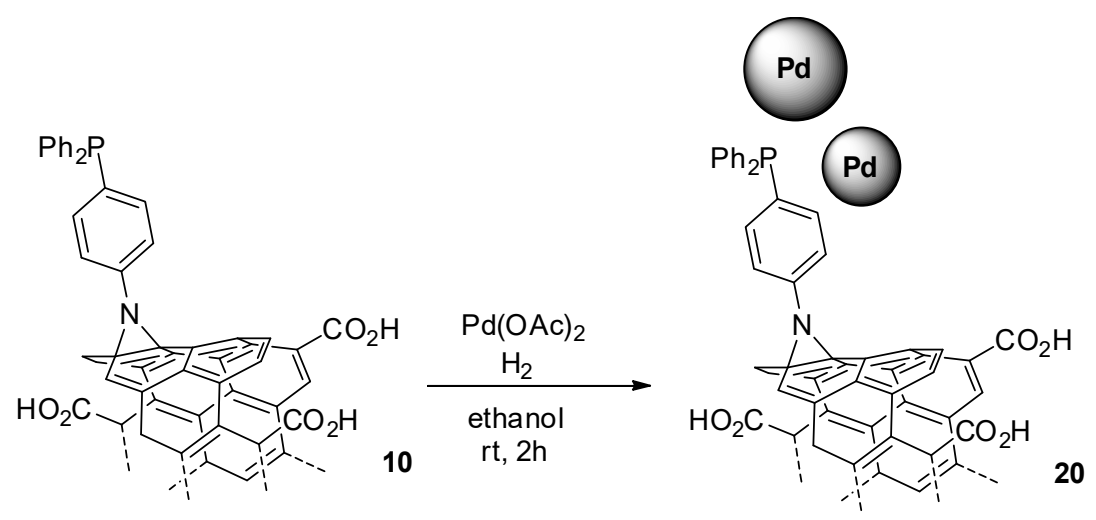

Scheme 5. Synthesis of nanocomposite 20.

The nanostructured material represented the carbon support for the effective catalyst: the nanoparticles synthesized from a palladium salt. TEM images confirmed the formation of nanoparticles (Figure 2a). The evaluation of their diameter distribution is showed in Figure $1 b$. ICP-plasma analysis estimated a loading degree of palladium $1.04 \pm 0.05 \mathrm{mmol} / \mathrm{g}$ for catalyst 20 . 


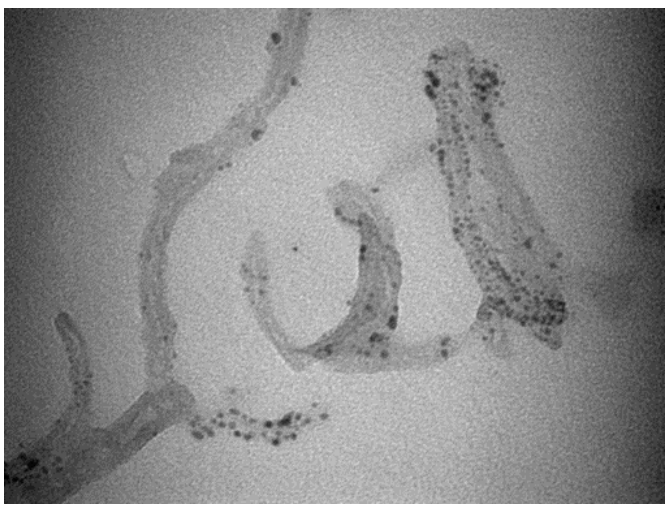

(a)

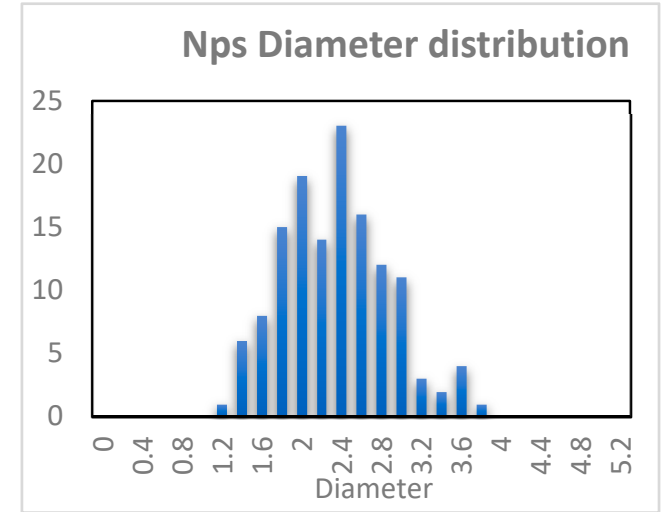

(b)

Figure 2. (a) Transmission electron microscopy (TEM) image of nanocomposite 20; (b) Size distribution of $\operatorname{Pd}(0)$ nanoparticles (mean value $=2.3 \mathrm{~nm}, \sigma=0.6 \mathrm{~nm}$.

In a previous experiment Fareghi et al. [24] synthetized trans-stilbene (24) (among many other substrates in a detailed study), via Heck reaction, in one cycle with $95 \%$ yield, exploiting a catalytic system consisting of immobilized Pd nanoparticles on phosphine-functionalized graphene. We tested catalyst 20 to synthesize the same product in four different cycles starting from iodobenzene (21) and styrene (22). (Scheme 6) The results are reported in Table 6 (Entry 1). Comparing the amount of Pd used by Fareghi and coworkers [24] (1.7 mol\%) with our system $20(0.92 \mathrm{~mol} \%)$, the results are good. In our case, the decrease in performance recorded for the last reaction cycle can be explained with a significant leaching of palladium. An ICP-AES analysis showed a metal loading of $0.18 \pm 0.05 \mathrm{mmol} / \mathrm{g}$ after the fourth reaction cycle, suggesting a loss of $80 \%$ of the catalytic species.

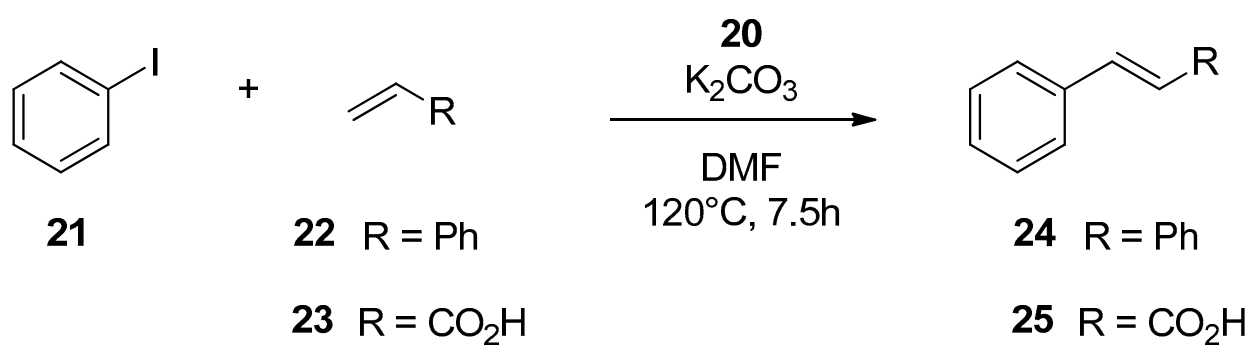

Scheme 6. Heck reactions between iodobenzene 21 and olefins catalyzed by 20.

Table 6. Catalytic Heck reaction: yields over the different cycles.

\begin{tabular}{ccccccc}
\hline Entry & Olefin & Amount of Pd (mmol \%) & Cycle 1 & Cycle 2 & Cycle 3 & Cycle 4 \\
\hline 1 & $\mathbf{2 2}$ & 0.97 & $66 \%$ & $89 \%$ & $90 \%$ & 37 \\
2 & $\mathbf{2 3}$ & 0.12 & $58 \%$ & $61 \%$ & 61 & 51 \\
\hline
\end{tabular}

Better results were obtained in the synthesis of trans-cinnamic acid in which the catalyst loading could be lowered down to $0.12 \%$ of active Pd species preserving an acceptable yield up to the fourth cycle (Table 6, Entry 2).

\section{Conclusions}

The decoration of MWCNT with phosphine oxide derivatives has demonstrated a straightforward method to produce new nanostructured material with promising properties as catalysts. Although the limited efficiency of the processes study, this is, to the best of our knowledge, the first example of an organocatalytic processes based on phosphine oxides that has been transferred to heterogeneous 
materials. Further optimization of the reaction conditions, more detailed study of the chemical-physical features of the catalysts, and their applications to further reaction will be the object of future studies.

Supplementary Materials: The following are available online at http://www.mdpi.com/2311-5629/6/3/57/s1, Figures S1-S8: NMR, IR and MS spectra of starting phosphine oxide derivatives 5 and its precursor A. Figure S9: TEM imageof ox-CNT 2. Figures S10-S15 IR spectra of nanostructured materials 2, 6, 7, 8, 9, 10. Figures S16-S25: ${ }^{1} \mathrm{H}$ NMR spectra and MS spectra of compounds 13, 18, 19, 24 and 25.

Author Contributions: M.C.L. performed the catalytic studies and synthetized the catalysts, A.F. synthetized the starting phosphine oxide derivatives, G.B. contributed to the synthesis of the catalysts and their characterization. G.S. performed and interpreted the XPS analyses. K.M.P. project administration. S.C. conceptualization and writing. All authors have read and agreed to the published version of the manuscript.

Funding: M.C.L.: G.B., S.C. thank MIUR-Italy ("Progetto Dipartimenti di Eccellenza 2018-2022" allocated to Department of Chemistry "Ugo Schiff").

Conflicts of Interest: The authors declare no conflict of interest.

\section{References}

1. Guo, H.; Fan, Y.C.; Sun, Z.; Wu, Y.; Kwon, O. Phosphine Organocatalysis. Chem. Rev. 2018, 118, 10049-10293. [CrossRef] [PubMed]

2. Aroyan, C.E.; Dermenci, A.; Miller, S.J. The Rauhut-Currier reaction: A history and its synthetic application. Tetrahedron 2009, 65, 4069-4084. [CrossRef]

3. Bednarek, C.; Wehl, I.; Jung, N.; Schepers, U.; Bräse, S. The Staudinger Ligation. Chem. Rev. 2020, 120, 4301-4354. [CrossRef] [PubMed]

4. Fletcher, S. The Mitsunobu reaction in the 21 st century. Org. Chem. Front. 2015, 2, 739-752. [CrossRef]

5. Maercker, A. The Wittig Reaction. In Organic Reactions; American Cancer Society: Atlanta, GA, USA, 2011; pp. 270-490. ISBN 978-0-471-26418-7.

6. Appel, R.; Knoll, F.; Miche, W.; Morbach, W.; Wihler, H.-D.; Veltmann, H. Reaktionen im Zweikomponentensystem Triphenylphosphin/Tetrachlormethan1). Chem. Berichte 1976, 109, 58-70. [CrossRef]

7. O’Brien, C.J.; Nixon, Z.S.; Holohan, A.J.; Kunkel, S.R.; Tellez, J.L.; Doonan, B.J.; Coyle, E.E.; Lavigne, F.; Kang, L.J.; Przeworski, K.C. Part I: The Development of the Catalytic Wittig Reaction. Chem. A Eur. J. 2013, 19, 15281-15289. [CrossRef] [PubMed]

8. O'brien, C.J. Catalytic Wittig and Mitsunobu Reactions 2010. U.S. Patent 8,901,365, 2 December 2014.

9. Kosal, A.D.; Wilson, E.E.; Ashfeld, B.L. Phosphine-Based Redox Catalysis in the Direct Traceless Staudinger Ligation of Carboxylic Acids and Azides. Angew. Chem. Int. Ed. 2012, 51, 12036-12040. [CrossRef]

10. Buonomo, J.A.; Aldrich, C.C. Mitsunobu Reactions Catalytic in Phosphine and a Fully Catalytic System. Angew. Chem. Int. Ed. 2015, 54, 13041-13044. [CrossRef]

11. Van Kalkeren, H.A.; van Delft, F.L.; Rutjes, F.P.J.T. Organophosphorus Catalysis to Bypass Phosphine Oxide Waste. ChemSusChem 2013, 6, 1615-1624. [CrossRef]

12. Voituriez, A.; Saleh, N. From phosphine-promoted to phosphine-catalyzed reactions by in situ phosphine oxide reduction. Tetrahedron Lett. 2016, 57, 4443-4451. [CrossRef]

13. Campisciano, V.; Gruttadauria, M.; Giacalone, F. Modified Nanocarbons for Catalysis. ChemCatChem 2019, 11, 90-133. [CrossRef]

14. Liang, Y.N.; Oh, W.-D.; Li, Y.; Hu, X. Nanocarbons as platforms for developing novel catalytic composites: Overview and prospects. Appl. Catal. A Gen. 2018, 562, 94-105. [CrossRef]

15. Iglesias, D.; Melchionna, M. Enter the Tubes: Carbon Nanotube Endohedral Catalysis. Catalysts 2019, 9, 128. [CrossRef]

16. Abousalman-Rezvani, Z.; Eskandari, P.; Roghani-Mamaqani, H.; Salami-Kalajahi, M. Functionalization of carbon nanotubes by combination of controlled radical polymerization and "grafting to" method. Adv. Colloid Interface Sci. 2020, 278, 102126. [CrossRef] [PubMed]

17. Negri, V.; Pacheco-Torres, J.; Calle, D.; López-Larrubia, P. Carbon Nanotubes in Biomedicine. Top. Curr. Chem. (Z) 2020, 378, 15. [CrossRef] [PubMed]

18. Vázquez, E.; Giacalone, F.; Prato, M. Non-conventional methods and media for the activation and manipulation of carbon nanoforms. Chem. Soc. Rev. 2013, 43, 58-69. [CrossRef] 
19. Tasis, D.; Tagmatarchis, N.; Bianco, A.; Prato, M. Chemistry of Carbon Nanotubes. Chem. Rev. 2006, 106, 1105-1136. [CrossRef]

20. Karousis, N.; Tagmatarchis, N.; Tasis, D. Current Progress on the Chemical Modification of Carbon Nanotubes. Chem. Rev. 2010, 110, 5366-5397. [CrossRef]

21. Liu, X.; Tang, B.; Long, J.; Zhang, W.; Liu, X.; Mirza, Z. The development of MOFs-based nanomaterials in heterogeneous organocatalysis. Sci. Bull. 2018, 63, 502-524. [CrossRef]

22. Savateev, A.; Antonietti, M. Heterogeneous Organocatalysis for Photoredox Chemistry. ACS Catal. 2018, 8, 9790-9808. [CrossRef]

23. Biagiotti, G.; Langè, V.; Ligi, C.; Caporali, S.; Muniz-Miranda, M.; Flis, A.; Pietrusiewicz, K.M.; Ghini, G.; Brandi, A.; Cicchi, S. Nanostructured carbon materials decorated with organophosphorus moieties: Synthesis and application. Beilstein J. Nanotechnol. 2017, 8, 485-493. [CrossRef] [PubMed]

24. Fareghi-Alamdari, R.; Haqiqi, M.G.; Zekri, N. Immobilized $\operatorname{Pd}(0)$ nanoparticles on phosphine-functionalized graphene as a highly active catalyst for Heck, Suzuki and N-arylation reactions. New J. Chem. 2016, 40, 1287-1296. [CrossRef]

25. Zhang, Y.; Chu, W.; Xie, L.; Sun, W. Preparation and Catalytic Performance of Carbon Nanotube Supported Palladium Catalyst. Chin. J. Chem. 2010, 28, 879-883. [CrossRef]

26. Shirley, D.A. High-Resolution X-Ray Photoemission Spectrum of the Valence Bands of Gold. Phys. Rev. B 1972, 5, 4709-4714. [CrossRef]

27. Moulder, J.F.; Chastain, J. Handbook of X-Ray Photoelectron Spectroscopy: A Reference Book of Standard Spectra for Identification and Interpretation of XPS Data; Physical Electronics: Eden Prairie Minnesota, MN, USA, 1995; ISBN 978-0-9648124-1-3.

28. Zhang, X.; Liu, H.; Hu, X.; Tang, G.; Zhu, J.; Zhao, Y. Ni(II)/Zn Catalyzed Reductive Coupling of Aryl Halides with Diphenylphosphine Oxide in Water. Org. Lett. 2011, 13, 3478-3481. [CrossRef] [PubMed]

29. Pietrusiewicz, K.M.; Zablocka, M. Optically active phosphine oxides. 3. Conjugate Adddition to Vinyl Phosphine Oxides in Aqueous Conditions. Tetrahedron Lett. 1988, 29, 937-940. [CrossRef]

30. Maj, A.M.; Pietrusiewicz, K.M.; Suisse, I.; Agbossou, F.; Mortreux, A. Chiral $\beta$-Aminophosphine Oxides as Ligands for Ruthenium Assisted Enantioselective Transfer Hydrogenation of Ketones. Tetrahedron Asymmetry 1999, 10, 831-835. [CrossRef]

31. Brandi, A.; Cicchi, S.; Goti, A.; Koprowski, M.; Pietrusiewicz, K.M. Kinetic Resolution in 1,3-Dipolar Cycloaddition of Tartaric Acid-Derived Nitrones to 2,3-Dihydro-1-phenyl-1H-phospholes. An Enantioselective Approach to the 2,2'-Coupled Pyrrolidine-Phospholane Ring System. J. Org. Chem. 1994, 59, 1315-1318. [CrossRef]

32. Goti, A.; Cicchi, S.; Brandi, A.; Pietrusiewicz, K.M. Nitrone cycloadditions to 2,3-dihydro-1-phenyl-1H-phosphole 1-oxide. Double asymmetric induction and kinetic resolution by a chiral nitrone. Tetrahedron Asymmetry 1991, 2, 1371-1378. [CrossRef]

33. Bahr, J.L.; Tour, J.M. Highly Functionalized Carbon Nanotubes Using in Situ Generated Diazonium Compounds. Chem. Mater. 2001, 13, 3823-3824. [CrossRef]

34. Schmidt, G.; Gallon, S.; Esnouf, S.; Bourgoin, J.P.; Chenevier, P. Mechanism of the Coupling of Diazonium to Single-Walled Carbon Nanotubes and Its Consequences-Schmidt. Chem. A Eur. J. 2009, 15, 2101-2110. [CrossRef] [PubMed]

35. Holzinger, M.; Vostrowsky, O.; Hirsch, A.; Hennrich, F.; Kappes, M.; Weiss, R.; Jellen, F. Sidewall Functionalization of Carbon Nanotubes. Angew. Chem. Int. Ed. 2001, 40, 4002-4005. [CrossRef]

36. Cotton, F.A.; Barnes, R.D.; Bannister, E. 442. The effect of complex-formation by phosphine oxides on their P-O stretching frequencies. J. Chem. Soc. 1960, 2199-2203. [CrossRef]

(C) 2020 by the authors. Licensee MDPI, Basel, Switzerland. This article is an open access article distributed under the terms and conditions of the Creative Commons Attribution (CC BY) license (http://creativecommons.org/licenses/by/4.0/). 